\title{
Benznidazole biotransformation in rat heart microsomal fraction without observable ultrastructural alterations: comparison to Nifurtimox-induced cardiac effects
}

\author{
María Montalto de Mecca, Laura C Bartel, Carmen Rodríguez de Castro, José A Castro/+ \\ Centro de Investigaciones Toxicológicas (CEITOX-CITEFA/CONICET), J B de La Salle 4397, Villa Martelli, B1603ALO Buenos Aires, Argentina \\ Benznidazole (Bz) and Nifurtimox (Nfx) have been used to treat Chagas disease. As recent studies have de- \\ monstrated cardiotoxic effects of Nfx, we attempted to determine whether Bz behaves similarly. Bz reached the \\ heart tissue of male rats after intragastric administration. No cytosolic Bz nitroreductases were detected, although \\ microsomal NADPH-dependent Bz nitroreductase activity was observed, and appeared to be mediated by P450 \\ reductase. No ultrastructurally observable deleterious effects of Bz were detected, in contrast to the overt cardiac \\ effects previously reported for Nfx. In conclusion, when these drugs are used in chagasic patients, Bz may pose a \\ lesser risk to heart function than $N f x$ when any cardiopathy is present.
}

Key words: Chagas disease - benznidazole - nifurtimox - nitroreduction - cardiopathy

Chagas disease (American trypanosomiasis) is an endemic parasitic disease caused by the Trypanosoma cruzi. Life-threatening myocarditis can occur during the acute phase, resulting in a $10 \%$ mortality rate and development of chronic Chagas disease in $10-50 \%$ of the survivors. The chronic form of the disease is characterized by potentially lethal cardiopathy (Pinto Dias 2000, Pinto Dias et al. 2002, Sosa-Estani \& Segura 2006).

Nifurtimox (Nfx) and Benznidazole (Bz) are available for the etiological treatment of this disease. The use of these drugs during the acute phase is widely accepted. While their efficacy in the chronic phase is still under investigation, this treatment plan is based on the hypothesis that Chagas cardiomyopathy may be triggered by persistent parasitic infection (Wen et al. 2006). Side effects are a major drawback to the application of these drugs (Coura \& de Castro 2002, Castro et al. 2006). Toxic side effects of both drugs require enzymatic reduction of the nitro group and are mainly mediated by cytochrome P450 (CYP), cytochrome P450 reductase and partially by xanthine oxidoreductase (XOR) or aldehyde oxidase (AO). Bz toxicity derives from the generation of reactive intermediates that covalently bind to macromolecules (Docampo \& Moreno 1985, Castro et al. 2006). In the case of Nfx, however, the unstable Nfxnitroanion radical that is formed reacts with oxygen by a redox cycling mechanism to produce reactive oxygen species and stressful oxidative conditions (Docampo \& Moreno 1985, Castro et al. 2006).

Financial support: FONCyT Argentina (PICT/00 5-9941), UNSAM Argentina (SP06/090)

+ Corresponding author: jcastro@citefa.gov.ar

Received 9 April 2008

Accepted 7 August 2008
Recent studies from our laboratory showed that Nfx induced biochemical and ultrastructural alterations in rat heart tissue (Bartel et al. 2007). These findings might be particularly relevant, given that cardiac manifestations of the disease have critical implications for treated patients. No equivalent studies are available in the literature concerning potential effects of $\mathrm{Bz}$ on the heart, despite the fact that $\mathrm{Bz}$ has been used as the drug of choice in many Latin American countries, not only to treat the acute or indeterminate phases of the disease, but also in patients who have entered the chronic phase (Viotti et al. 1994, 2006, Fabbro et al. 2000, Gallerano \& Sosa 2000, Coura \& de Castro 2002, García et al. 2005, Sosa-Estani \& Segura 2006).

The present work describes the results of experiments in which potential effects of $\mathrm{Bz}$ in the rat heart were measured under experimental conditions equivalent to those reported for Nfx (Bartel et al. 2007).

\section{MATERIALS AND METHODS}

Animals and treatment - Non-inbred male Sprague Dawley rats (10 weeks, 260-300 bw) were employed. Procedures used for breeding, housing and handling animals were in accord with guidelines set by the Administración Nacional de Medicamentos, Alimentos y Tecnología, Buenos Aires. Food and water were available ad libitum except for the in vitro studies in which they were fasted 12-14 h. Animals were given a single intragastric (ig) dose of Bz (N-benzyl-2-nitroimidazole1-acetamide) at $100 \mathrm{mg} / \mathrm{kg} \mathrm{bw}$, in $1 \%$ carboxymethylcellulose (CMC), while control rats received only $1 \%$ CMC (5 per group). For chemical and enzymatic studies, animals were sacrificed by decapitation and hearts were rapidly excised and processed.

Distribution - The determination of Bz content was made at 1, 3 and $6 \mathrm{~h}$ after ig $\mathrm{Bz}$ administration. Sample clean-up was carried out with an Extrelut ${ }^{\circledR}$ column and final analysis was done by HPLC. A Hewlett Packard model 1090 Series II HPLC with an HP ODS Hypersil 
column $(200 \times 2.1 \mathrm{~mm}$ i.d., $5 \mu \mathrm{m}$ particle size $)$ and an HP diode array detector were used. The mobile phase, consisting of $60 \%$ methanol in water, was delivered at a constant flow-rate $(0.2 \mathrm{ml} / \mathrm{min})$ and the column effluent was monitored at $320 \mathrm{~nm}$ (Díaz et al. 2000). Bz was quantified by peak-area ratio with respect to a calibration curve, which was made with the identically-treated standard between 15-85 $\mu \mathrm{M}\left(\mathrm{r}^{2}=0.9999\right)$. The detection limit was $4.0 \mathrm{nmol} \mathrm{Bz} / \mathrm{g}$ heart tissue with a signal to noise ratio of three. The recovery of Bz added to a cardiac homogenate was greater than $80 \%$.

$B z$ nitroreductase activity - Isolation of microsomal and cytosolic fractions from pooled heart tissue was performed as previously described (Masana et al. 1984). Nitroreductase activity was determined by anaerobic incubations run in $20 \mathrm{~mL}$ septum-sealed flasks, for $60 \mathrm{~min}$ periods. The incubation mixtures contained $0.1 \mathrm{mM} \mathrm{Bz}$ and $20 \mathrm{mM}$ phosphate buffer, $\mathrm{pH} 7.4$, in a final volume of $2.5 \mathrm{~mL}$. In order to evaluate the cytosolic nitroreductase activity, the incubation mixture contained cytosol (8.0$12.0 \mathrm{mg} \operatorname{prot} / \mathrm{mL}$ ) and hypoxanthine or N-methylnicotinamide. To inhibit activity, allopurinol or menadione was added. To determine the microsomal nitroreductase activity, the incubation media contained the cellular fraction (2.0-3.0 mg prot $/ \mathrm{ml})$ and a NADPH-generating system (Masana et al. 1984). Known inhibitors of CYP and flavoenzymes such as carbon monoxide (CO), alphaphenyl-alpha-propylbenzeneacetic acid, 2-(diethylamino) ethyl ester (SKF 525-A) and diphenyleneiodonium chlo-

\section{TABLE I}

Benznidazole concentration in rat cardiac tissue from five independent determinations

\begin{tabular}{cc}
\hline Treatment time $(\mathrm{h})$ & $\begin{array}{c}\text { Bz concentration (nmol/g tissue) } \\
(\text { mean } \pm \mathrm{SD})^{a}\end{array}$ \\
\hline 1 & $66.28 \pm 11.9$ \\
3 & $45.93 \pm 18.07$ \\
6 & $29.27 \pm 8.60^{b}$
\end{tabular}

$a$ : values from five independent determinations; $b: \mathrm{p}<0.05 \mathrm{vs} 1 \mathrm{~h}$. ride (DPI) were also used. Nitroreductase activity was followed spectrophotometrically at $320 \mathrm{~nm}$ by substrate decreases that were linear with time and protein content under the experimental conditions employed (Bartel et al. 2007). Protein concentration was determined with Folin-Ciocalteu reagent (Lowry et al. 1951).

Transmission electron microscopy - Following $24 \mathrm{~h}$ of treatment, animals were anesthetized with sodium pentobarbital $(70 \mathrm{mg} / \mathrm{kg}$ bw). The thorax was opened and a cold fixative buffer ( $2 \%$ formaldehyde, $2 \%$ glutaraldehyde in a $100 \mathrm{mM}$ cacodylate buffer containing $0.02 \% \mathrm{CaCl}_{2}, \mathrm{pH} 7.4$ ) was gently injected into the left ventricle, through the pulmonary vein. Hearts were removed and each left ventricle was cut off in 10 blocks under fixative. These blocks were washed in barbital buffer and post-fixed with $1 \%$ osmium tetroxide. They were then stained with uranyl acetate, followed by dehydration in an ascending ethanol series and propylene oxide, and finally embedded in epoxy resin. The sections $(1 \mu \mathrm{m})$ were stained with toluidine blue and examined under a light microscope in order to select areas for thin sectioning. Thin sections, cut with a diamond knife and mounted on copper grids (300 meshe), were stained with uranyl acetate and lead citrate and examined in a Philips EM300 transmission electron microscope (de Castro et al. 1992).

Statistical analysis - Significant differences between mean values were assessed by the analysis of variance test and the Tukey posttest (Gad 2001). Calculations were performed using Graph Pad software (GraphPad Instat, version 2.0). For all analyses, the criterion of significance was set at $\mathrm{p}<0.05$.

\section{RESULTS}

Distribution and nitroreductase activity - Bz was absorbed and reached the heart within the tested periods. The drug concentration decreased significantly after $6 \mathrm{~h}$ of administration (Table I). There was no evidence of nitroreductive $\mathrm{Bz}$ metabolism in the cytosolic fraction in the presence of either hypoxanthine or N-methylnicotinamide. However, the microsomal fraction exhibited

TABLE II

Benznidazole $(\mathrm{Bz})$ nitroreductase activity in microsomal fraction

\begin{tabular}{|c|c|c|c|}
\hline & & $\begin{array}{l}\text { Bz-nitroreductase activity }{ }^{a} \\
(\mathrm{pmol} / \mathrm{mg} \text { protein } \mathrm{min})^{b}\end{array}$ & $\%$ inhibition \\
\hline \multirow[t]{4}{*}{ Cytosol } & Hypoxanthine & nd & \\
\hline & Allopurinol & nd & \\
\hline & N-methylnicotinamide & nd & \\
\hline & $\mathrm{N}$-methylnicotinamide + Menadione & nd & \\
\hline \multirow[t]{5}{*}{ Microsomes } & without NADPH & nd & \\
\hline & NADPH $(0.5 \mathrm{mM})$ & $93.3 \pm 22.4^{c}$ & \\
\hline & $\mathrm{NADPH}+\mathrm{CO}$ & $44.7 \pm 30.5$ & 52 \\
\hline & NADPH + DPI $(10 \mu \mathrm{M})$ & $16.8 \pm 19.7$ & 82 \\
\hline & NADPH + SKF 525-A (3mM) & $56.7 \pm 19.1$ & 39 \\
\hline
\end{tabular}

$a$ : incubations were done at $37^{\circ} \mathrm{C}\left(\mathrm{N}_{2}\right.$ atmosphere); $b$ : values are mean $\pm \mathrm{SD}(\mathrm{n}=3) ; c: \mathrm{p}<0.01$ vs without NADPH and NADPH + DPI; nd: not detected. 
a NADPH-dependent nitroreductase activity that was significantly inhibited by DPI (Table II). Pure CO and SKF 525-A induced an inhibitory trend that was not statistically significant. The lack of significance might be attributed to the variability in the data caused by the low level of activities present and the indirect method of activity determination.

Electron microscopy - The observed ultrastructure of the control rat hearts was not different from that described by others (Haschek \& Rousseaux 1998) (Fig. 1A). In effect, ventricular myocytes contain one or two nuclei, myofibrils, mitochondria, sarcoplasmic reticulum and $\mathrm{T}$ tubules, glycogen particles and other organelles. The contractile elements occupied about $50 \%$ of the cytoplasm of myocytes and form a continuous mass that is separated into myofibrils of varying size. Myofibrils were highly ordered arrays of dark anisotropic A bands and light anisotropic I bands. I bands were bisected by a thick, dark $\mathrm{Z}$ band. Ventricular myocytes were rich in
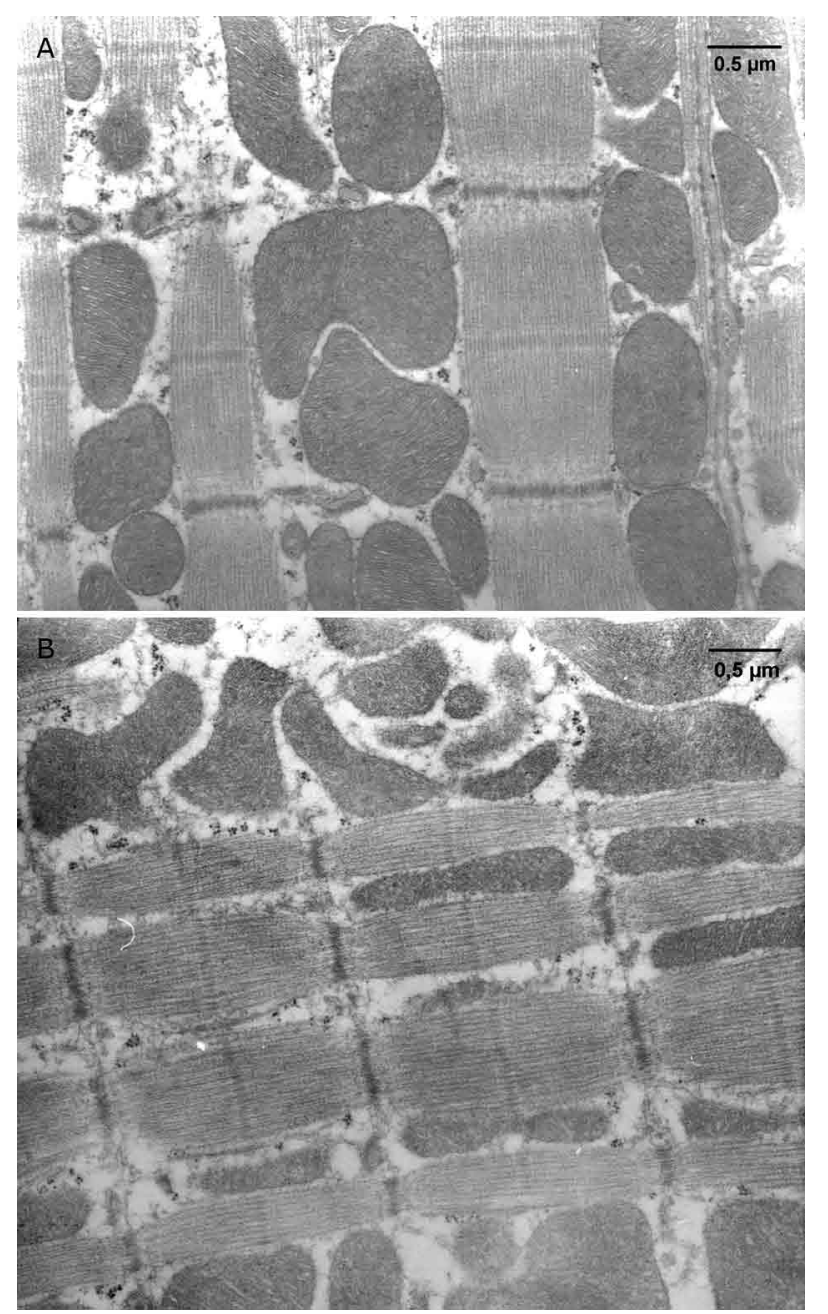

Fig. 1A: ventricular myocyte from control CMC-treated rat. Myofibrils are relaxed and have prominent A (dark) and I (light) bands bisected by a thick dark $\mathrm{Z}$ band; 17, 600X. B: ventricular myocyte from Bz-treated rat. The contractile material is subdivided by rows of mitochondria of typical myocardial control cells; 17, 600X. mitochondria, which constituted about $35 \%$ of the cell volume and were situated between myofibrils. The Bztreated group did not show any morphological changes in cellular ultrastructure (Fig. 1B). This result contrasted with that observed in the Nfx-treated animals, included for comparison, which clearly showed alterations in cardiac ultrastructure at the level of the myofibrils and mitochondria (Fig. 2).



Fig. 2: ventricular myocyte from Nfx-treated rat. It shows severe fragmentation into components of myofibrils, disintegration of mitochondrial membrane and cristae disappearance, 17, 600X.

\section{DISCUSSION}

Our studies of $\mathrm{Bz}$ content in heart tissue demonstrate the presence of $\mathrm{Bz}$ in this organ at 1,3 and $6 \mathrm{~h}$ after ig administration. The ready presence of $\mathrm{Bz}$ in this tissue is not unexpected in light of the high liposolubility of this drug. Considering that $\mathrm{Bz}$ reached the heart and that microsomes could potentially metabolize it, nitrocompound bioactivation might be expected to occur in situ. This effect could be clinically relevant, as it is known that the toxic effects induced by Bz require initiation of a nitroreductive process that produces highly reactive metabolites, which are able to covalently bind to macromolecules (Gorla et al. 1986, Castro et al. 2006). We did not detect any Bz-induced cytosolic nitroreductive biotransformation, such as that seen in liver and other organs, which is mediated by XOR and/or AO (Castro et al. 2006, Masana et al. 1984).

The microsomal metabolism of $\mathrm{Bz}$ reported in the present study proceeded only in the presence of NADPH as a cofactor, suggesting that, as in the case of other organs, the P450/P450 reductase system was involved (Castro et al. 2006). However, the intensity of this $\mathrm{Bz}$ nitroreductive process was 7-fold smaller than that observed in the case of Nfx (Bartel et al. 2007). A fraction of that low activity could be attributed to the participation of reduced P450 itself, as suggested by the tendency of inhibition (statistically non-significant) by 
$\mathrm{CO}$ and SKF 525-A. These two inhibitors are very well established for their specific effects on P450-mediated biotransformation of xenobiotics (Gillette et al. 1972). Cytochrome P450-related enzymes are known to be present in the heart and to be relevant for both its health and disease (Elbekai \& El-Kadi 2006). The intensity of the inhibitory effect of DPI on the microsomal nitroreduction, as compared to the effects of either CO or SKF 525-A, suggests that, besides any participation of P450 reductase via reducing P450 itself, DPI would also be able to directly reduce $\mathrm{Bz}$ without $\mathrm{P} 450$ participation. In effect, DPI is a well known inhibitor of microsomal P450 reductase activity (McGuire et al. 1998) in the heart as well as in other organs (Castro et al. 2006). It is important to emphasize that the $\mathrm{Bz}$ nitroreductive metabolism was previously shown to be particularly susceptible to the presence of oxygen (Masana et al. 1984). This is because the $\mathrm{Bz}$ nitroreduction process is not accompanied by redox cycling when oxygen is present, in contrast to what happens in the case of Nfx (Docampo \& Moreno 1985). The far lower intensity of $\mathrm{Bz}$ nitroreduction as compared to that of $\mathrm{Nfx}$ and the markedly intense effect of oxygen might reasonably explain why, unlike $\mathrm{Nfx}$, $\mathrm{Bz}$ does not lead to ultrastructurally visible deleterious effects (e.g., cytoplasm vacuolization, separation and loss of myofibrils, mitochondrial swelling) (Bartel et al. 2007). This oxygen inhibitory effect might be of special relevance in the case of very highly oxygenated organs such as the heart.

From the clinical point of view, the distinct behaviours of these drugs should be noted, not only when heart damage is already present, as in the chronic phase, but also in the indeterminate phase, when $T$. cruzi-infected individuals may be developing a potential cardiac symptom. In fact, $\mathrm{Bz}$ has been used not only in the acute phase, but also in the indeterminate and even in the chronic phase with some positive results, according to several researchers (Viotti et al. 1994, 2006, Pinto Dias et al. 2000, Fabbro et al. 2000, 2007, García et al. 2005, Reyes \& Vallejo 2005, Sosa-Estani \& Segura 2006). In light of the above described considerations, the potential use of $\mathrm{NfX}$ in the chronic or even in the indeterminate phase of Chagas disease should be considered with caution, since oxidative damage was reported to occur during development of the cardiomyopathy itself (Wen et al. 2006). Any sources of oxidative stress, such as those potentially induced by $\mathrm{Nfx}$, including increased protein carbonyl content or decreased protein sulfhydryl content (Bartel et al. 2007), would be additive to and perhaps exacerbating of those already present in the heart during T. cruzi infection.

The available studies were independently analyzed by Reyes and Vallejo (2005). They concluded that there is still insufficient evidence to support the efficacy of either drug as a recommended treatment for chronic chagasic cardiopathy, if overt heart disease is present. The present observations suggest that among the drugs currently available for treatment of Chagas disease, $\mathrm{Bz}$ poses less of a risk to heart function than Nfx, if any cardiopathy is already present.

\section{REFERENCES}

Bartel LC, Montalto de Mecca M, Fanelli SL, Rodríguez de Castro C, Díaz EG, Castro JA 2007. Early Nifurtimox-induced biochemical and ultrastructural alterations in rat heart. Hum Exp Toxicol 26: 781-788.

Castro JA, Montalto de Mecca M, Bartel LC 2006. Toxic side effects of drugs used to treat Chagas' disease (American Trypanosomiasis). Hum Exp Toxicol 25: 471-479.

Coura J, de Castro SL 2002. A critical review on Chagas disease chemotherapy. Mem Inst Oswaldo Cruz 97: 3-24.

de Castro CR, de Toranzo EGD, Castro JA 1992. Benznidazole-induced ultrastructural alterations in rat adrenal cortex. Mechanistic studies. Toxicology 74: 223-232.

Díaz EGD, de Castro CR, de Mecca MM, Castro JA 2000. Benznidazole-induced ultrastructural and biochemical alterations in the rat colon. Acta Pharmacol Sin 21: 961-966.

Docampo R, Moreno SN 1985. Biochemical toxicology of antiparasitic compounds used in the chemotherapy and chemoprophylaxis of American Trypanosomiasis (Chagas' disease). Rev Biochem Toxicol 7: 159-204.

Elbekai RH, El-Kadi AO 2006. Cytochrome P450 enzymes: Central players in cardiovascular health and disease. Pharmacol Ther 112: 564-587.

Fabbro de Suasnábar D, Arias E, Streiger M, Piacenza M, Ingaramo M, Del Barco M, Amicone N 2000. Evolutive behavior towards cardiomyopathy of treated (nifurtimox or benznidazole) and untreated chronic chagasic patients. Rev Inst Med Trop São Paulo 42: 99-109.

Fabbro DL, Streiger ML, Arias ED, Bizai ML, del Barco M, Amicone NA 2007. Trypanocide treatment among adults with chronic Chagas disease living in Santa Fe city (Argentina), over a mean follow-up of 21 years: parasitological, serological and clinical evolution. Rev Soc Bras Med Trop 40: 1-10.

Gad SC 2001. Statistics for toxicologists. In AW Hayes, Principles and methods of toxicology, 4th ed., Taylor \& Francis, Philadelphia, USA, p. 285-364

Gallerano RR, Sosa RR 2000. Interventional study in the natural evolution of Chagas' disease. Evaluation of specific antiparasitic treatment. Retrospective-prospective study of antiparasitic theraphy. Rev Fac Cien Med Univ Nac Cordoba 57: 135-162.

García S, Ramos CO, Senra JF, Vilas-Boas F, Rodrigues MM, Campos de Carvalho AC, Ribeiro dos Santos R, Soares MB 2005. Treatment with benznidazole during the chronic phase of experimental Chagas' disease decreases cardiac alterations. Antimicrob Agents Chemother 49: 1521-1528.

Gillette JR, Davies DC, Sasame HA 1972. Cytochrome P450 and its role in drug metabolism. Annu Rev Pharmacol 12: 57-84.

Gorla N, Diaz Gomez MI, Castro JA 1986. Interaction of benznidazole reactive metabolitos with rat liver deoxyribonucleic acid and nuclear proteins. Arch Int Pharmacodyn Ther 280: 22-31.

Haschek WM, Rousseaux CG 1998. Cardiovascular and skeletal muscle systems. In WM Haschek, CG Rousseaux, Fundamentals of toxicologic pathology, Academic Press, New York, USA, p. 309-335.

Lowry OH, Rosebrough NJ, Farr AL, Randall RJ 1951. Protein measurement with the Folin phenol reagent. J Biol Chem 193: 265-275.

Masana M, de Toranzo EG, Castro JA 1984. Reductive metabolism and activation of benznidazole. Biochem Pharmacol 33: 1041-1045.

McGuire JJ, Anderson DJ, McDonald BJ, Narayanasami R, Bennett BM 1998. Inhibition of NADPH cytochrome P450 reductase and 
glyceryl trinitrate biotransformation by diphenyleneiodonium sulfate. Biochem Pharmacol 56: 881-893.

Pinto Dias JC 2000. Epidemiología. In Z Brener, Z Andrade, MT Barral-Netto. Trypanosoma cruzi e doença de Chagas, 2nd ed., Guanabara Koogan, Rio de Janeiro, Brasil, p. 48-74.

Pinto Dias JC, Silveira AC, Schofield CJ 2002. The impact of Chagas disease control in Latin America. A review. Mem Inst Oswaldo Cruz 97: 603-612.

Reyes PA, Vallejo M 2005. Trypanocidal drugs for late stage, symptomatic Chagas disease (Trypanosoma cruzi infection). Cochrane Database Syst Rev 19: CD004102.

Sosa-Estani S, Segura EL 2006. Etiological treatment in patients infected by Trypanosoma cruzi: experience in Argentina. Curr Opin Infect Dis 19: 583-587.

Viotti R, Vigliano C, Armenti A, Segura E 1994. Treatment of chronic Chagas' disease with benznidazole: clinical and serologic evolution of patients with long-term follow-up. Am Heart J 127: 151-162.

Viotti R, Vigliano C, Lococo B, Bertocchi G, Petti M, Alvarez MG, Postan M, Armenti A 2006. Long-term cardiac outcomes of treating chronic Chagas disease with benznidazole versus no treatment. Ann Intern Med 144: 724-734.

Wen JJ, Yachelini PC, Sembaj A, Manzur RE, Garg NJ 2006. Increased oxidative stress is correlated with mitochondrial dysfunction in chagasic patients. Free Radic Biol Med 41: 270-276. 